\title{
Trust and Mistrust in Sources of Scientific Information on Climate Change and Vaccines
}

\author{
Insights from Portugal and Poland
}

\author{
Jussara Rowland ${ }^{1}$ (D) - João Estevens ${ }^{1}$ (D) . Aneta Krzewińska ${ }^{2}$ (D) Izabela Warwas $^{3}$ (D) \\ Ana Delicado ${ }^{1}$ (D)
}

Accepted: 9 November 2021 / Published online: 9 January 2022

(C) The Author(s), under exclusive licence to Springer Nature B.V. 2021

\begin{abstract}
Public trust in science and expertise remains a contentious issue. When public trust is analysed, it often simplifies a complex process of information retrieval and interpretation. Questionnaire surveys help us make sense of differences among actors and countries, but they fail to provide a comprehensive analysis of the reasons that lead citizens to trust a specific actor to differing degrees. Hence, we opted for using a qualitative grounded approach to understand how citizens make sense of their trust in several actors. This article draws from the results of public consultations with citizens in Portugal and Poland about two specific science-related topics_climate change and vaccines-focusing on citizens' perceptions of trust in several sources of scientific information. The results show that citizens' trust varies depending on the source of scientific information, and it is affected by the topic's visibility and different national levels of institutional trust. It also concludes that citizens use different criteria to evaluate trustworthiness and that this process leads to different ways of expressing trust/mistrust: unquestioned confidence, justified trust, reflexive trust, and active distrust. Such knowledge leads to a more in depth understanding of how trust in science is constructed, which can help science communicators and educators choose sources and materials.
\end{abstract}

\section{Introduction}

Trust in science has been extensively examined in the field of science studies over the years. In the early days of the "public understanding of science (PUS) 'industry"” (Gregory $\&$ Miller, 1998), the worrying lack of support for science among the public was attributed to a lack of scientific knowledge (the origin of the "deficit model") and of trust in science

Jussara Rowland

jussara.rowland@ics.ulisboa.pt

1 Instituto de Ciências Sociais da Universidade de Lisboa, Lisbon, Portugal

2 Instytut Socjologii, Uniwersytet Łódzki, Lodz, Poland

3 University of Lodz, Lodz, Poland 
(Yearley, 2005). Reprising Lewenstein's (1992) work, much of the PUS tradition relies on the belief that if citizens learned more about science, they would accept it, make more informed choices and decisions, and trust scientific experts. This lack of knowledge and trust was usually diagnosed through questionnaire surveys that included true/false questions about scientific "facts" and direct questions on whether the respondents trusted scientists or not (Allum et al., 2008; Bauer, 2008). Variations in knowledge and trust were analysed through crosstabs with sociodemographic variables, such as sex, age, educational attainment, and country of residence.

Traditional ways of tackling the knowledge and trust deficit by providing more information to the public have failed to deliver results. In fact, crises and controversies that question the authority and reliability of science, such as BSE (or "mad cow disease") and GMO (genetically modified organisms), have only further undermined public trust (Wynne, 2006; Tlili \& Dawson, 2010; Pieczka and Escobar, 2013; Dierkes \& Von Grote, 2005). The solution proposed was to promote more public engagement with science, following a "dialogical model" (Yearley, 2005; Wynne, 2006; Haywood and Besley, 2014) . And yet, as Yearley (2005) puts it, science communication continues to see public distrust as a problem to be solved. For him, this reduces trust to an issue that only has to do with the public, whereas trust is essential for the relationships among scientists: "Trust is an indispensable component in the creation and passing on of scientific knowledge; it is not restricted to lay audiences for science, and it is not a feature that can be technically manipulated to promote high-trust conditions" (Yearley, 2005: 158). Furthermore, for Yearley, trust is not static - neither for individuals nor institutions - as it is an outcome of interactions and negotiations.

This article aims to contribute to the discussion on the role of trust in science by addressing the specific issue of trust in sources of scientific information. We aim to explore the reasoning used by citizens to trust or distrust different institutional and individual actors that provide scientific information to the public. Whereas most studies rely on a quantitative (survey-based) assessment of public trust in science (in general), ours is a qualitative approach based on an analysis of discussions during public consultations about two specific science-related topics (climate change and vaccines). Scientific information circulates in a large ecosystem that includes both institutional and individual actors, such as Research \& Innovation institutions, scientists, journalists and science communicators, the general media, educators, companies, and the general public. Here we focus on a set of actors that are seen as sources of scientific information (and not channels of information). Thus, we assess how citizens perceive these actors in terms of trust and distrust, identifying which actors they consider more reliable to provide scientific information and how they justify their positions in relation to different actors.

The article is based on a European project, CONCISE Communication Role on Perception and Beliefs of EU Citizens about Science (H2020 SwafS), which included public consultations with citizens about this topic. It draws from the results of consultations in two countries-Portugal and Poland. Qualitative comparative studies are important because they allow us to contrast different realities and explore similarities and differences among cases (Azarian, 2011). In this case, the comparative dimension of the study can help discover convergences and divergences on the issue of trust and mistrust assessment and enlighten how national contexts can affect different orientations towards sources of science information. Portugal and Poland present an interesting comparative choice because of their difference in the approach to science and science communication. The European comparative study MASIS (RTD-L1-PP-2008-MASIS), about policy and research activities on science in society, concluded that in Poland, there is relatively high interest in science 
education, but interest in "democratisation of policy making" is weaker (Kozłowski, 2011). It also showed that the use of science for policy-making in Poland is not formalised, and the actual impact of scientists' findings on citizens' decisions is relatively low. Portugal, on the other hand, is at the other end of the scale-MASIS showed the use of science for policy-making is highly formalised, and the influence of scientists' findings on citizens' decisions in the country is strong (Mejlgaard et al., 2012). Poland, as a post-socialist country in Central and Eastern Europe, does not have much tradition in science communication, whereas Portugal has had a national agency for the promotion of science communication since 1996 and a dedicated budget for it (Gonçalves \& Castro, 2003; Miller et al., 2002).

International surveys also seem to indicate that there are differences in the levels of science trust and institutional trust between the two countries, with Poland presenting lower values. According to the Wellcome Global Monitor 2018, for example, only 23\% of the Polish population declare that they trust science a lot (vs 53\% in Portugal) and 27\% declare that they trust college and university scientists to do work that benefits the public (vs $48 \%$ in Portugal) (Gallup, 2019). In the Standard Eurobarometer (European Commission, 2019), on the other hand, both countries present low levels of trust in national institutions - the government and parliament - compared to the European average, but there are differences. In Poland, only $34 \%$ of the respondents trusted the government (vs $46 \%$ in Portugal), 30\% trusted the parliament (vs 39\% in Portugal), and 22\% trusted political parties (the same value for Portugal).

There are also differences in terms of the general perception of the topics discussed. The topic of vaccines and vaccination has been widely discussed in Poland in recent years, with increasing debates on social media and the rise of negative perceptions associated with the topic (Warwas et al., 2021). The activities of the anti-vaccination movement have led to a considerable loss of confidence in vaccinations and the medical personnel carrying them out (Matkowska-Kocjan, 2018). This was not the case in Portugal in 2019, where vaccine acceptance was high (Larson, et al., 2018) and anti-vax movements were almost nonexistent (this has since changed since COVID-19, although vaccine hesitancy is still low). In relation to climate change, the Eurobarometer survey carried out in September 2019 showed that $87 \%$ of respondents in Portugal consider it a very serious problem, but only $70 \%$ do in Poland. Portugal has a long tradition of climate action policies, in particular, renewable energies (Carvalho et al., 2014). In Poland, on the other hand, despite efforts on climate policy and climate change mitigation, the country is still affected by its dependency on coal production, and its presence in the country imaginaries (Kuchler \& Bridge, 2018).

The article begins with a short theoretical background of the object of analysis and then describes the data and methodological procedures. The results section aggregates data according to institutional actors (public institutions, universities and research centres, civil society organisations, companies) and individual actors (politicians, scientists, practitioners, public figures), accompanied by illustrative quotes from the discussions. The discussion and conclusion not only highlight the similarities and differences between countries and topics, but they also propose divergent types of trust and distrust that show the complexity of the links between scientific information and the public. 


\section{Theoretical Background}

The wealth of studies about trust in science communication shows that this field of study is still committed to solving the problem of public trust in science. Sanz-Menéndez and CruzCastro (2019) identified three approaches in the literature of the field that point to different explanatory factors for trust in science:

(a) knowledge and education, based on the approach of the deficit model, which insists on the role of interests and information regarding science as relevant variables; (b) values and beliefs, culturally based rather than rationally assessed, related to attitudes towards S\&T [Science \& Technology] impacts or risk assessments and

(c) the difference in trustworthiness and reputation that citizens attribute to different social institutions or professions (Sanz-Menéndez \& Cruz-Castro, 2019: 536)

Of these three approaches, it is the trustworthiness of institutions and professionals that interests us most for this article. Trust is developed within a context that shapes and structures its development towards different actors. Weingart and Guenther (2016) state that the public perception of trust varies among sources, and it needs to be assessed within the specifics of the social context, which are complex and encompass contested interests. Nevertheless, in general, as Weingart and Guenther summarised, there are some trends that must be taken into consideration:

Institutions that are associated with general values such as 'justice' and 'commonwealth', or orientation to the 'common good'-e.g., constitutional courts and science-command a particularly high level of trust. (...) medical doctors, teachers, judges together with scientists are on the top of the scales when asked whom to trust most-all professions that are perceived to serve the common good-while politicians and industrialists are near the bottom (...) It is by virtue of competition that jobs are created which, in turn, produce income. But success in competition is built on the pursuit of self-interest. (Weingart \& Guenther, 2016: 6-7)

Sanz-Menéndez and Cruz-Castro (2019) developed an experimental approach to assess the effect of different social institutions through which scientific information is provided on the credibility that citizens award to science, focusing particularly on the topic of the evolution of $\mathrm{CO} 2$ emissions in Spain. They conclude that citizens tend to trust universities and R\&D institutions, the IPCC, and Greenpeace more. Conversely, the citizens tend to award less credibility to the information provided by the government and by business associations. They also ascertain that different factors have different weights in awarding credibility to different sources. A positive view of the effects of S\&T on the environment corresponds to higher levels of credibility in Greenpeace, universities, and R\&D institutions. Confidence in "governments and public administration" is correlated with the higher credibility of government sources. The credibility of Greenpeace and IPCC is also higher among those who express more confidence in non-governmental organisations.

The layers on how citizens assess a specific actor also encompass the specifics of their role in society or their job. Scientists and scientific institutions are pivotal sources of scientific information. According to Borchelt (2008), there are three important components of trust in science that are associated with how scientists and scientific institutions are perceived: competence (the ability to do the work that is expected of them, the reputation of the researchers), integrity (distinguishing right from wrong, ethical concerns, consideration 
of harmful impacts, transparency and honesty) and dependability (doing the right thing even under pressure).

Additionally, as suggested by Krause et al. (2019), trust in scientists varies depending on who employs them or the topic being discussed. Based on an analysis of surveys in the USA and Europe, they verified that trust is slightly lower when it comes to environmental topics and scientists employed by companies. Pechar et al. (2018) narrowed down the factors that affect trust in science to attitudes towards government and corporations. Focusing on the topics of climate change and GMOs, and based on surveys in Germany and the US, they concluded that "the more favourable an individual's attitude is towards corporations, the more that individual will trust the science of GMOs, and the more favourable an individual is towards government, the more likely it is that this individual will trust the science of climate change" (Pechar et al., 2018: 294-295).

Hendriks et al. (2016) argued that epistemic trust rests not only on the assumption that one is dependent on the knowledge of others who are more knowledgeable, but it also demands that citizens be critical and vigilant about the sources. There are three characteristics that determine the epistemic trustworthiness of a science-based information source such as a scientist or a scientific institution: expertise, integrity and benevolence. The public tends to trust scientific sources that are seen as experts in their fields but that also have moral integrity (i.e. that are not swayed by vested interests) and do useful work for the benefit of society-in line with what was suggested by Weingart and Guenther (2016).

In surveys, the public seems to trust science less when considering specific issues, such as nuclear energy or genetically modified food, for example, than science in general (Hendriks et al., 2016). Indeed, trust seems to depend on the specificities of each topic, hence the relevance of examining briefly how the literature addresses trust in climate change science and trust in vaccines, the topics under analysis in this article.

In regard to climate change, several studies are concerned with how trust in science is influenced by political ideology, namely, that it is lower among conservatives (Republicans in the US) than among liberals (Democrats) (McCright \& Dunlap, 2011). However, McCright et al. (2013) propose that conservatives show less trust in "science that identifies environmental and public health impacts of economic production (i.e. impact science)" and more trust in science "that provides new inventions or innovations for economic production (i.e. production science)". Another strand of research deals with trust in science as a factor for acting to mitigate climate change. Cologna and Siegrist (2020) performed a metaanalysis of previous studies to ascertain that trust in scientists and environmental groups correlates positively with climate-friendly behaviour. The relation is less clear regarding trust in institutions, which influence public behaviours more than private ones.

When analysing climate science scepticism in a rural US state, through 33 interviews with residents of Idaho who identified themselves as sceptical about climate change, Sarathchandra and Haltinner (2020) identified three distinct dimensions: (1) concerns about incentive structures in science that could bias the conclusions about climate issues, (2) the accuracy of data and models used by climate scientists and (3) perceived practices of science and scientists as exclusionary. Both trust and mistrust perceptions do not exist in a vacuum; hence it is important to mention that each topic is a specific topic, as their analysis showed that "(...) trust in science depends on the topics under consideration, perceived competence and trustworthiness of scientists, views about science as an authoritative system of knowledge, and how science is applied in society vis-à-vis production, policy, and/ or regulation". (Sarathchandra \& Haltinner, 2020: 54). 
Interestingly, several studies also contrast climate change and vaccines in terms of trust. Hamilton et al. (2015) examined survey results in the USA to assess whether the proposition of opposite biases holds true: the assertion that conservatives tend to oppose the scientific consensus on climate change or evolution, while liberals oppose science on some other topics, such as vaccines. However, their results disprove this proposition: liberal/democrats tend to trust science more in both cases. Lewandowsky et al. (2013) reached different conclusions by analysing the results of an internet survey: they ascertained that conservatism and a free-market worldview are strongly correlated with the rejection of climate science, but when it comes to vaccines, a more nuanced relationship appears. Libertarians oppose government intrusion arising from mandatory vaccination programs, whereas liberals distrust pharmaceutical companies.

Nevertheless, the issue of trust in vaccines raises specific questions. As a topic where the science is mostly "consolidated" (notwithstanding the novel coronavirus vaccines, as well as the Human Papilloma Virus vaccine created in 2006), other kinds of actors gain prominence as sources of scientific information: physicians and government health departments. Thus the literature tends to focus more on how trust and mistrust of these actors influence parents' attitudes and behaviours. Raithatha et al. (2003) found that parents expressed feelings of dread about the risks of vaccination and had doubts about the scientific knowledge around vaccines, as well as mistrust of government agencies (exacerbated by risk stories such as BSE) and medical doctors (caused by scandals around incentive payments). Leask et al. (2006) performed a qualitative study to explore how parents respond to conflicting messages about vaccination in mass media. They concluded that parental decision-making about vaccination is strongly influenced by personal experiences with vaccine-preventable diseases, value systems and level of trust in health professionals-especially family doctors who took the time to explain procedures and discuss risks. Institutional trust also plays a role here: "There was also discussion about government where some expressed scepticism that the 'government is only telling you what they WANT you to know' while others found it hard to see why the government would pay large amounts for immunisation programmes without good reason" (Leask et al., 2006: 7242).

On the other hand, going back to the deficit/dialogue model mentioned earlier, Goldenberg (2016) questions the notion that vaccine hesitancy stems from a deficit of knowledge and conversely proposes that it is due mostly to public mistrust of scientific experts and institutions. She blames misguided official responses and poor communication practices: shutting down dissenting views and amplifying the pro-vaccine message does not work because it gives the impression that the scientific establishment is suppressing "inconvenient truths" and does little to address public concerns. According to Goldenberg (2016: 564), "public dissent does not reside in anti-science ideology or a misunderstanding of science. Instead, many parents approach the question of vaccine safety from a different perspective-concern for their children - and this individualised approach makes the presence of rare but serious adverse events a safety priority rather than, as health officials see it, a reasonable risk". Goldenberger states that though communication is not a panacea, dialogical communicative practices can help address the specific concerns of the citizens and encourage trust by the lay public. For the public to accept the scientific consensus view, it requires some degree of trust in scientific experts. That trust is built upon "repeated practices of communicating responsibly" through which "scientific bodies build their reputations for being responsive to public interests".

In questionnaire surveys, low levels of trust can often be understood as mistrust. However, Van De Walle and Six (2014) suggest that trust and mistrust are two distinct concepts, arguing that we should distinguish between "a lack of trust" and "distrust" in institutions. 
They believe that distrust is not the absence of trust but a different disposition. Quoting Lewicki et al., (1998: 439), they consider that trust is the "confident positive expectations regarding another's conduct", while mistrust consists of "confident negative expectations regarding another's conduct". Mistrust, then, is associated with the expectation of harm and dishonesty, i.e. with perceived intent. A lack of trust, on the other hand, is not necessarily mistrust, but an absence of trust, the result of a reflexive process about the trustworthiness of institutions. The authors rely on Krouwel and Abts (2007) to show that citizens develop their trust based on reason and reflexivity, not on routine, generalised trust. This creates an alert system that demands control mechanisms be put in place in legitimate distrust situations. Through careful analysis, active distrust can be taken away, while active trust takes place (Walle \& Six, 2014: 164).

This theoretical review showed that trust in different scientific information sources can be recognised and assessed dissimilarly in our societies. Hence, we must consider several actors involved in disseminating scientific information. In addition, the dissemination of scientific information occurs in different social and cultural contexts, which leads to citizens' distinct perceptions of similar actors. Thus, we take into consideration two European countries with diverse social, political and historical characteristics. Last, we noted that trust is also shaped by the specifics of different scientific topics, thus the need to include two distinct topics in the research design: climate change (environment) and vaccines (health).

Finally, the limitations of quantitative analyses regarding what leads to high or low levels of trust in science and how trust and mistrust towards different actors are constructed led us to consider that a different approach was needed. We believe our qualitative analysis can contribute to a better understanding of how citizens assess trust in sources of scientific information and its role on how trust in science is constructed.

\section{Data and Methods}

This article is based on information gathered through the EU funded project CONCISE"Communication role on perception and beliefs of EU Citizens about Science"-which involves five countries: Italy, Poland, Portugal, Slovakia and Spain. The main objective of this project was to understand the role science communication plays on the origin of beliefs, perceptions and knowledge concerning four scientific issues: climate change, vaccines, genetically modified organisms and complementary and alternative medicines. The core activity of this project was 1-day public consultations with a diverse sample of citizens in each country. Qualitative data was collected from group discussions during the consultations. The concise consultation script covered three dimensions: sources and channels of scientific information, trust/mistrust in sources of information and suggestions to improve science communication.

For this article, we focus on the second part of the discussions, where the participants debated the reliability of and trust/mistrust in sources of information. During this section, the participants were asked: (1) what sources of information they search for each specific topic, (2) what their favoured sources are (and why) and (3) how they decide if a source is trustworthy when they receive information. The discussions allowed us to understand who their preferred sources of information are but also how they perceive and rationalise trust and mistrust in relation to different providers of scientific information. 
In this article, we compare two countries with different social and political landscapes (Portugal and Poland) and two topics — climate change (henceforth identified as CC) and vaccines (identified as VAX), both with high visibility (although with COVID vaccines, the latter has since become a much more controversial topic).

In each consultation, we sought to recruit 100 residents, illustrating the diversity of each country's population regarding gender, age, education level, place of residence, disability and national minorities. Registration for the consultations was widely publicised on social media, in mailing lists, and through intermediary organisations (libraries, associations). This sampling strategy aimed to achieve representativeness in a typological rather than statistical sense, i.e. all values of the variables of interest were present in the sample. Stewart and Shamdasani (1990: 53) use the term "convenience" to refer to such a sample, which means that the sample contains all the values of the variables that also occur in the population. This type of selection allows researchers to make careful generalisations about transversal opinions or behaviours from the sample to the population. This allowed us to obtain diverse opinions and points of view and to better understand shared but varied representations and rationalisations on these topics.

The consultations had 102 participants in Portugal and 100 in Poland. Although we used the country's sociodemographic characteristics as sub-quotas in the recruitment and selection process, as we were dependent on the willingness of the citizens to participate in a full-day event on science communication, during the weekend, the final sample was unbalanced. In both countries, there was an over-representation of women (67\% in Portugal, 63\% in Poland) and people with a university degree (68\% in Portugal, $48 \%$ in Poland). We achieved greater diversity in terms of age (different age groups), occupation (multiple sectors and backgrounds) and place of residence (although with an over-representation of urban areas).

Based upon the Responsible Research and Innovation (RRI) concerns, the participants were considered partners in the research process. This was taken into account during the whole preparation for the consultation process and especially during the recruitment phase. The participants were provided with a comprehensive set of information on the conditions for participating in the public consultations, which were clearly articulated in the Informed Consent document given to them for voluntary approval. They also received clarification of any concerns and detailed information about the security of personal data. The participants voluntarily registered in the online system and those who were not computer-literate received support on entering data from a recruiting consultant. The participants also received follow-up information about the project and a summary of the research findings.

The consultations took place in September 2019 in Lodz (Poland) and November 2019 in Lisbon (Portugal). The participants were divided into 12 discussion tables of 8-10 people. Each discussion took place under the supervision of a moderator and an observer. Each topic was discussed separately for approximately 1 hour, and all participants took part in all four rounds of the discussions. The discussions were recorded (each round corresponds to 12 hours of recording) and transcribed in full. For this paper, we analysed 48 group discussions ( 24 on climate change and 24 on vaccines) on the issue of trust in sources of scientific information.

This empirical material was initially analysed using NVivo 12 Pro. The content analysis was carried out by two team members from each country. We used a shared code tree, allowing us to identify common categories that participants often mentioned during the discussions. Through this analysis, we were able to identify the main sources mentioned in the discussion and recode them into different types of sources, either institutional or individual. 
Data related to the different types of actors were then further analysed for each country and topic. We used a grounded approach, which allowed us to move beyond descriptions and to construct concepts that explain what is happening (Charmaz, 2006). Our focus here was not quantitative, i.e. how frequently an actor was mentioned and by whom, but qualitative, i.e. what are the underlying transversal patterns that shape the participants' assessment of trust and mistrust in relation to both institutional and individual sources of scientific information? The data from each country were then synthesised through memo writing (Charmaz, 2006) and subsequently compared during a multi-step process. To ensure higher levels of reliability, the analysis involved an interactive process of interpretation among all the authors of the paper. This allowed us to better contextualize the data, make crosscountry and topic comparisons for each actor and highlight similarities and differences. Our findings generate insights on the way trust and mistrust are conceptualised in relation to different sources of scientific information and also how these perceptions are mediated by topic and national context. Due to the size and composition of the samples, however, they are not generalizable and cannot be directly translated in terms of measurable results.

In the next section, we report our findings by source, using illustrative quotes of the phenomena described. We identify each quote with regard to country (PT or PL), topic (CC or VAX), gender (M, F), age group and level of education (sec-secondary education or he-higher education).

\section{Results}

The institutional actors mentioned by the participants and identified during the analysis were political institutions, scientific institutions, civil society institutions and companies. We considered political institutions those organisations-national or international-that create, enforce or apply laws and regulations. We included state-related institutions such as the Government, but also international institutions (UN, OECD, etc.), European institutions or public administration bodies such as the National Health Directorate or the National Environmental Agency in this group. We considered scientific institutions the organisations that perform research like universities or research centres. Civil society institutions are the non-state, not-for-profit or voluntary organisations formed by citizens. So, we included, for example, community-based organisations, as well as non-governmental organisations (NGOs). Last, we considered a fourth group, business - made up of private companies and corporations. Finally, the individual actors identified were politicians (politicians in general or politicians referred to by name), scientists (scientists in general or scientists mentioned by name), public figures (well-known personalities related to the topic) and practitioners (health professionals). For each actor, we considered the main arguments used to justify trust and mistrust and the differences between topics and countries.

\subsection{Trust in Institutional Actors}

\subsubsection{Political Institutions}

International institutions seem to be more relevant to the participants in the topic of climate change (since they mentioned the United Nations, UNESCO, IPCC and the European 
Commission) than in the topic of vaccines (where only the World Health Organisation (WHO) and the European Union were mentioned). In general, these international institutions are positively assessed since participants considered them to be credible institutions that do not face the pressures national governments do nor are they subject to a conflict of interest between their mission and private interests. They also valued their expertise and stressed their role on controlling the expansion of anti-science movements.

The WHO has done studies to prove and to, let's say, take away the credibility of what the [anti-vax] movements, both in the United Kingdom and in the United States, [say]. [PT_VAX_M_45-54_sec].

However, in the case of vaccines in Poland, some participants questioned the authority of the WHO, suggesting it was vulnerable to the lobbying of some companies while also developing unethical tests in developing countries.

In general, the WHO is doing experiments somewhere over there in African countries... It looks bad. [PL_VAX_M_45-54_sec]

In the case of national institutions, opinions were more ambivalent. There is widespread consensus regarding the trustworthiness of technical agencies, such as the Chief Sanitary Inspectorate in Poland (mentioned both in vaccines and climate change) and the National Health Directorate (NHD) in Portugal (mentioned only in the case of vaccines). These institutions were considered trustworthy because they have experts working for them; hence, they provide science-based advice to government representatives without participating in political disputes.

As far as trust in public institutions in our country is concerned, (...) considering that the main one responsible for arranging the vaccination calendars is the Chief Sanitary Inspectorate. It is an institution that I have a lot of trust in as it supervises all the activities in the country, issues appropriate announcements (...). [PL_VAX_F_4554_he]

I trust the Health Ministry. That they include the necessary vaccines in the national vaccination plan. [PT_VAX_F_65+_sec]

However, there was also one participant that looked at the National Health Directorate's work as being too oriented to one specific goal, becoming slightly biased in its mission to promote vaccination.

The National Health Directorate is always a bit biased [in favour of vaccines] (...) because it's their mission. [PT_VAX_F_55-64_he]

Governments in both countries are not as trusted as technical agencies. Although the Ministry of Health is seen as a credible source when it comes to vaccines, it is not visible enough in the public space, according to consultation participants. In addition, the Ministry of the Environment and the Prime Minister in Poland were criticised for their lack of competence when it comes to speaking out on climate change issues. This civic distrust was also influenced by disputes between politicians and unclear appointments of party members to the highest public offices.

It is important for me (...) to feel the difference between state institutions, such as the Office of Weights and Measures, and government institutions, such as the Prime Minister's Office, because it is obvious that regardless of who is in power, the second ones will be politicised, and the first ones are specialists who know how to weigh and 
how to measure, regardless of whether they are for this or that party. [PL_CC_F_4554_he]

In Portugal, in the climate change discussions, national institutions were seldom referred to directly, though the participants occasionally mentioned reports, local plans, local initiatives or conferences made available or organised by public authorities as a trusted source of information (especially by participants who work in education or in local municipalities).

I always use [CC] references (...) The municipalities have the EMAACs, which are the municipal strategies of adaptation to climate change. You also have the ENAC

[National Climate Change Strategy], you have... There are so many references... [PT_CC_M_55-64_he]

Moderator: Why those sources?

They are more credible. [PT_CC_M_55-64_he]

Finally, also in the climate change discussions, a few participants referred to the politicisation of this topic. They gave the example of the 2019 general elections in Portugal and how political parties incorporated the climate change narrative only because the electorate finds it relevant. In Poland, a participant stated that politicisation harms the credibility of information because the message needs to match political needs; hence, sometimes, they are a source of disinformation.

I will start with these state institutions (...) they should be associated with something reliable, and unfortunately for me, they are not, because of, e.g., their policy of disinformation on energy or climate in Poland. So it's definitely not a data source for me [PL_CC_F_35-44_he].

\subsubsection{Trust in scientific institutions}

When discussing climate change, the participants mainly referred to scientific institutions as trustworthy sources. Interestingly, when discussing this topic, the Polish participants mentioned state-affiliated research institutes rather than universities. They also said that they trust these institutes when they employ professionals (scientists) working in the field and systematically conducting research. At the same time, they emphasised that it is important for these institutes to be independent of external political or economic pressures. However, some participants questioned whether it is possible to speak of independent research when it is always funded in some way, whether from public or private sources. It is important to note that, contrary to what can be found in the literature in this area (Krause et al., 2019; Pechar et al., 2018), for a group of participants, private funding of research was considered to be less of a threat to the independence of researchers than if public funds were allocated to this research. Once again, the participants emphasised that they found the relationship between research and politics troubling.

There are independent scientific institutes not funded by the state because the fact that research is funded by the state does not guarantee its independence. [PL_ CC_F_35-45_he]

In Portugal, when discussing climate change, research institutions and universities are mentioned in a very broad way, but always as credible sources of information. Their connection with civil society and schools, in particular, was valued, especially at the local level. One participant, however, also pointed to the risks associated with universities/ 
research engaging with controversial stances on this topic, since this might affect not only their image as trustworthy institutions, but the message they want to convey to the general public. This participant gave the example of a university that hosted a climate denial conference in 2019.

I was outraged at the time, and people said: 'Ah, no, but the University of Porto only rents the place'. (...) That space has the minimum respectability associated with the title. And as long as you put deniers and scientists, or flat-earthers on the same level of the scale, I mean, we're not going anywhere. And for the average person who doesn't understand anything, who has difficulty decoding scientific messages, who can't even access or understand the statistical issues behind it very well, then they see 'ah, these guys are scientists too, they went to the University of Science'. This is chaos; this [conference] blows up a year of well-done communication [PT_ CC_M_45-54_he]

In the case of vaccines, there were almost no discussions that specifically mentioned research centres or universities. This may be due to the fact that the participants consider vaccines "established knowledge" rather than the result of current scientific research (in pre-COVID days). Nevertheless, the participants talked very broadly of their trust in research information, research papers and scientific sources (on this, see also trust in scientists below), and they also expressed concerns regarding private financing of research centres by pharmaceutical companies (on this, see below trust in companies).

\subsubsection{Trust in Civil Society Organisations}

Civil society organisations were only mentioned as a source of information on the topic of climate change. The only international NGO named was Greenpeace. In Portugal, Greenpeace was mentioned in four tables but in a very casual way, as an organisation that works on the topic. In one case, a participant asked if it still existed because she had not heard of them recently. In Poland, there were a few statements by participants about Greenpeace, and the evaluation of its activities was ambiguous. On the one hand, the positive impact of the actions undertaken by its activists was emphasised, e.g. shaping citizens' awareness of the need to protect the planet's resources. On the other hand, the activists' intentions were called into question, raising the suspicion that their actions were steered by hidden funders.

I have the same opinion about Greenpeace, for example, which I think also does a lot of bespoke actions. They are financed by certain circles, and they pursue their goals. Of course, there is a lot of money behind it (...). And this, it seems to me, leads to distortion [PL_CC_M_65+_sec]

This ambiguity concerning civil society organisations was not only directed to Greenpeace. The Portuguese participants often referred to NGOs as trustworthy because of their work in the field and commitment to the cause.

I would look for non-governmental organisations. The ones that are more credible, supposedly, the most credible, so it's in those organisations. Then, also in the international organisations, in the measures that they are taking, implementing, and all the, let's say, awareness-raising projects for the populations, for the governments themselves. [PT_CC_F_45-54_he] 
But some participants cautioned against NGOs' extremism. In some cases, Greta Thunberg is linked to international organisations, and the criticism directed at her also seems to apply to international environmental movements in general (on this, see also below).

Many times, environmental organisations fall into extremism. For example, I know that what I'm about to say is very controversial, but I still question the issue of the girl Greta, when there is a lot of exposure, there is something that starts to make me feel uncomfortable, I don't mean that I won't come to the conclusion that it was the exception, (...) and that it's all right, but it still impresses me because when they focus, certain the media today (...) I think they manipulate a lot. [PT_CC_F_45-54_ he]

Portuguese environmental NGOs were occasionally mentioned by the participants, namely, Quercus (3), Zero (2) and Sociedade Ponto Verde (1). They were always referred to as credible sources on the topic of climate change. Some participants expressed concern regarding the radicalism of some NGOs, but in this case, they talk generically, possibly including international ones in their assessment. There is no mention of distrust regarding specific Portuguese NGOs. In Poland, we found some very general statements concerning Polish NGOs that appeared with other environmental actors. These types of organisations-although not named - are trusted because of the results of their actions. It seems that the participants in the consultation were thinking mainly of small, locally operating foundations or associations whose activity they can observe directly.

I think scientists should work more with NGOs because they are like, for me, the most trusted organisations. [PL_CC_F_55-64_he]

The only mention to civil society organisations in the topic of vaccines came from Polish participants, who stated that they are important at the local level, especially to help disseminate ideas and make campaigns more effective.

Because the role of local governments is less important here, it is more a supporting role. And NGOs, they also have to have some support, of course. At least financially, so that these campaigns are really visible. [PL_VAX_M_45-54_he]

\subsubsection{Trust in companies}

Companies were more frequently mentioned in the discussions about vaccines than climate change. Pharmaceutical companies were assessed negatively, as they are associated with economic profit, conflictual private interests, and intense lobbying activities.

When we hear pharmaceutical companies talking about it, we might think "they are selling us something". [PT_VAX_M_45-54_sec]

Like every medical industry (...) maximising profits. That's all that matters. [PL_ VAX_M_45-54_he]

According to the participants, their activities can even create difficulties for doctors to understand the reliability of the information they are disseminating. Additionally, when governments and universities are linked with pharmaceuticals, their perceived trustworthiness is negatively affected.

Some universities have grants from laboratories; don't forget that is an issue. There is 
no total innocence of research. [PT_VAX_M_65+_he]

The pharmaceutical industry is often discredited because you can see that there are interests... and then it's a domino effect. And we distrust everything, because laboratory $\mathrm{x}$ is supporting the research of this or that university. [PT_VAX_F_45-54_he]

Although in Portugal participants expressed a consensual negative assessment regarding pharmaceutical companies, in Poland, a few participants who were more familiar with the sector mentioned that they made positive contributions by developing vaccines through intense research investment, even if they benefit from it in the end.

I work in the clinical research industry currently. And it is absolutely not the case that if big pharma funds a study, it has to be done the way they want it done. The clinical trials market is very simple. Whoever invents it wins for ten years. [PL_VAX_F_25-34_he]

Companies were perceived as trustworthy by some participants in the climate change discussions in Poland, since they believed that there are companies engaged in environmental protection and thus willing to introduce solutions to mitigate climate change. Yet, one participant also stated that these pro-environmental activities of private companies were a way to meet the expectations of pro-environmental customers who would later buy their products or use their services - in what is usually known as greenwashing (Laufer, 2003).

More and more organisations or even private companies are focusing on this and looking for it, because they know that the customers (...) are more and more ecoconscious; we want it to be natural and biodegradable. [PL_CC_F_25-34_he]

In Portugal, the participants in the climate change discussions perceived companies as a source of distrustful information, even if they were only seldom mentioned. Two types of criticism were made: private financing of studies that should be independent, hence raising doubts on the findings of these studies, and greenwashing.

But I see that behind it, there is a dishonest exploitation by many companies that take advantage of this fact to sell what does not exist. The fact that I have photovoltaic panels is an example. If I have photovoltaic panels and don't use my appliances during the day when my panels are producing energy, it is of no use. (...) So, does it make sense for me to invest that amount? From my point of view, it is dishonest. Some years ago, I saw the figures, the Prius was Toyota's car; it was the most ecological car. They compared it to a Ford car, and because the Prius had so many components, just the transportation of those components until it was assembled, it was like buying a Ford with 40,000 kilometres. [PT_CC_M_25-34_he]

\subsection{Trust in individual actors}

\subsubsection{Politicians}

During the climate change discussions, the participants mentioned politicians as important social actors who influence trust-building in scientific information. Both internationally known politicians and those with a national or even local reach were mentioned. In Portugal, there were negative statements about international politicians like Donald 
Trump (US President 2017-2021) and Jair Bolsonaro (the current President of Brazil). They were accused of ignorance on the subject, of actively promoting disinformation, and of being irresponsible because they disregard the consequences of their words and actions. The participants criticised the fact that these politicians cast doubt on the scientific fact of the anthropogenic causes of climate change and spread false information about the Amazon forest.

I'll give an example of what struck me negatively... it was Bolsonaro who said that it is the environmentalists who cause the environmental problems. Speaking of Trump, and specifically about the Amazon... they are the ones saying things like this... the so-called disinformation. [PT_CC_F_45-54_he]

In Poland, no international politician was mentioned by name, but participants contrasted Polish politicians with those from other countries. Thus, international politicians appeared as positively evaluated and trustworthy figures. Although this was not the dominant stance in the consultation, several participants said that politicians in other countries were more likely to listen to the arguments of experts and scientists, to refrain from using the topic of climate change in political disputes, and even (giving the example of France and Iceland) to use scientific findings as the basis for making decisions and implementing changes.

There are countries where the government listens more directly to the experts and does not process the information in terms of the current political fight, but they fight by implementing these expert indications. That is why, for example, in Iceland or France, there is very intensive reforestation. [PL_VAX_M_55-64_he]

Regarding politicians' roles as communicators and sources of trust/mistrust in climate change, there is a difference between the international and national spheres. In the Polish consultation, local politicians were mentioned quite often: in total, there were about forty statements related to politics, elections, pre-election campaigns and political parties. Yet, not all these statements were directly related to specific individuals or members of particular political groups.

Now, unfortunately, the subject of climate change is being politicised, and I do not know why. Some people from the right $(. .$.$) believe that climate change does not$ even exist. [PL_CC_M_55-64_sec]

Participants affirmed that politicians rarely made use of expert knowledge and that they consider climate change only as a tool in the struggle for power and not as an important problem. Therefore, in the perception of the participants in the Polish consultation, national politicians are not trusted when discussing climate change issues.

Politicians do not want to do it; they do not ask specialists. By the way, the cult of the scientist and the cult of knowledge have ceased to exist in Poland. He does not need the help of anything, he does not need to have an advisor who knows. (...) Additionally, our leading politicians speak about coal and air in such an insulting and authoritarian way. [PL_CC_M_55-64_he]

In contrast with the Polish consultation, there was no mention of national politicians in either topic in Portugal. 


\subsubsection{Scientists}

Scientists were mentioned by participants in the Portuguese consultation as trustworthy, especially when compared to other professional groups, such as journalists. This high degree of trust was mainly due to the fact that the opinions and positions communicated by scientists are based on scientific knowledge, so they are a reliable source of information on climate change or vaccines.

I pay attention, normally; if it is a specialist, I pay more attention; if it is a journalist, I pay much less attention, because there are those economic interests behind it and I never know when the news is biased and, therefore, I give some privilege to specialists and scientists. [PT_CC_F_65+_he]

Scientists are trusted because they are able not only to convey trustworthy information but also to justify their positions using their knowledge and the results of their research. Sustaining information in research results-their own or those of othersincreases the credibility of the statements made since research is based on scientific methods that are subjected to verification and control.

Starting from the basis that the scientific method is the closest thing we have to trust, that's it. It's the most reliable thing we have. I think science and the scientific method cannot have several opinions. It's not like certain subjects where we have several opinions; science is usually very objective, and there's not much room for other opinions. [PT_VAX_M_18-24_sec]

In the Polish consultation on vaccines, the participants unanimously expressed confidence in the scientists directly working on the subject and publishing scientific papers.

It is important that the article is written by someone with a scientific reputation who conducts clinical trials and so on. For example, among Polish doctors, there seems to be Professor M., who conducted clinical trials right there in the children's clinic (...) on the effects of vaccines on health. And for me, this person is credible. [PL_VAX_M_35-44_sec]

One participant pointed to epidemiologists as a reliable source of trust on information about vaccines.

The authorities on this matter are mainly epidemiologists. They deal with it on a daily basis, and as far as I am able to verify, the results of research in this field, well, their scientific papers, are also quite a good source... and they are definitely the greatest authority for me. [PL_VAX_M_25-34_he]

During the discussion, there was also an interesting point raised by one participant regarding the opinions of scientists. She stated that it is not the views of scientists that are important-if they are against vaccination, for example-it is the body of research on the topic, the scientific evidence that contributes to the general level of trust in science.

Well, that is the thing with science as a whole and scientists, that it doesn't matter what they think (...) That's not important. Only the research results matter. The results of studies, preferably such meta-analyses, of course, well there are such certain criteria. [PL_VAX_F_25-34_he] 
Besides recognising the research work carried out by scientists, other trust-inducing activities were highlighted: the dissemination of scientific output through conferences, educational campaigns, science festivals or science picnics. However, some concerns were raised about the independence of scientists. Participants in the Polish consultation questioned the results of the research financed either from public funds (granted by bodies with a particular political affiliation) or from private funds (directly financed by companies). In addition, they stressed that scientists could be forced to shape the conclusions of their research in line with the party's political agenda or to increase profit for company owners.

What scientific sources? If there is such a monopoly and all research is financed from state grants and all research financed by the industry sector says only one thing, then if it puzzles us, if we would question it, we would look somehow else, in some think-tanks, there are such independent scientific institutes, not financed by the state, because the fact that research is financed by the state does not guarantee its independence. [PL_CC_F_35-44_he]

Finally, some scientists were also identified by name during the discussions. This was most frequent in the case of active popularizers of science: in Poland, Szymon Malinowski, responsible for running the Science on Climate website; in Portugal, Luisa Schmidt, a sociologist who has been covering environmental issues in the media for several decades, and Filipe Duarte Santos, a (retired) climatologist and also a frequent presence in the media.

\subsubsection{Public figures}

In both countries, public figures were mentioned almost exclusively on the climate change topic, and the public figure that most stood out was Greta Thunberg. The young Swedish environmentalist is a polarising figure, and this is reflected in public perceptions about her. She is the main reason why participants said they heard about the topic on the news. In Portugal, however, some participants criticised her approach, saying that she overstated the problem, creating too much confusion. Her critics referred to the way she behaves and her style of communication:

As much as we may want to, when she spoke aggressively to the people she was talking to, she wasn't talking to just anyone, she was speaking in a very uncomplimentary way, with an aggressiveness that is not typical of a girl of that age, (...) she was being extremely overbearing to a group of very important people in there. [PT_CC_M_45-54_he]

Participants also pointed out the contradictions between her assertive message and her practices (lack of preparation, contradictory actions), which made her an object of mistrust, even when they agreed with the core message. Conversely, supporters of Greta Thunberg argued that she is a social phenomenon, a new format that reaches new audiences and moves people into action.

I want to clarify that Greta is not my source of scientific and reliable information. It is from the point of view of having a public impact and what it can do in terms of public opinion. There are a number of sources and scientists, and so on, that I read. (...) And Greta's follow-up, then Greta is in contact with politicians and scientists as well. So, that's the aspect. Now, as a social phenomenon, it has made some change 
from the point of view of awareness, not the scientific, academic, etc., absorption, but it moves people. [PT_CC_M_55-64_he]

In Poland, on the other hand, the image of Greta Thunberg was less contentious, thus more positive. The participants affirmed not only that they trust her message, but also her motives in relation to the topic.

Greta Thunberg, I think nobody has done that much so far. Of course, it's a very indirect influence, but if these topics are already in the news every day, whether you talk about this Greta, good or bad, it's no longer important. [PL_CC_F_34-44_he]

In the case of show business celebrities, the participants made quite positive statements. Their role in science communication was considered important because they draw attention to the issue and amplify important messages. Since celebrities have a large group of followers, they capture the public attention and can reach new audiences.

I think that it is important that they do this work since they are public figures and, therefore, put their image, let's say, at the service of others. It's not just the fame of the films and whatnot, but I think that if they're the ones communicating something or broadcasting something, they probably also attract other audiences. [PT_ VAX_F_45-54_he]

Leonardo DiCaprio, for example, was mentioned in both countries as someone who is considered personally engaged in climate change and that has worked on the topic for a long time. Consistency and coherence come from the fact that, unlike other influencers, he has been raising awareness about the subject since he was young, so he is considered particularly credible.

(...) there are many influencers who are paid to spread a certain message, regardless of the product. In this case, Leonardo di Caprio, as far as I know, has something innate in him, to be an environmentalist, to promote actions that improve the environment. I don't know if there is any coercion for him to spread these messages, or not, if he is associated with some NGO or not. But I do know that, from an early age, he shares these ideals of his on social networks, and so it reaches us very easily. [PT_CC_F_18-24_sec]

A similar justification was associated with $\mathrm{Al}$ Gore. The former vice-president of the US was often mentioned by the participants in Portugal but not as a politician but more as someone who talked about this topic earlier than everyone else. Many remember his 2006 documentary "An Inconvenient Truth" as the moment when they heard about this subject for the first time. He is considered a reliable source, even if one participant questioned the motive for the farming industry not being mentioned in his documentary.

I give all credit to $\mathrm{Al}$ Gore because he had the courage; after leaving the vice presidency of the United States, instead of retiring to Haiti or the Caribbean to smoke cigars and drink whisky, he embarked on a very complicated fight against the whole world. Because he was one of the first public figures that I have in my memory who went on television and came out with his chest to the bullets and said, "Guys, pay attention." (...) Greenpeace existed long before Al Gore, and there are other people, but the impact he had, because of what he had been before, probably stirred things up in a way that opened the eyes of many other people. [PT_CC_F_35-44_he] 
In contrast to international names, in Portugal, only one national celebrity was mentioned in one discussion as having a pro-environmental message (the TV host João Manzarra). In Poland, the national opinion leaders who were more often mentioned were Marcin Dorociński (an actor involved in the activities of the WWF) and Marcin Popkiewicz (co-editor of the "Science on Climate" website). Wojciech Cejrowski (a traveller) was mentioned in relation to the fires in the Amazon forest, and Katarzyna Bosacka (a journalist) was mentioned because her programs were considered a reliable source of information that showed the tangible effects of climate change from the perspective of the individual.

Some participants in Poland also named science popularizers who have their own YouTube channels. The participants emphasised that they are interesting people who are able to create interest in the subject. In this case, what is praised is their style and their appeal to different audiences.

I also like Polish YouTubers, popularizers of science, who, of course, may not be doing research themselves, but at least are honest about it. And that would be $\mathrm{Mr}$ Rożek or just SciFan, "Scientific babble". Yes, those are cool programmes. There are also a lot of interesting niche blogs related to climate, like the "Arctic blog", where every day, this scientist analyses the ice caps, the changes, and publishes everything. [PL_CC_F_35-44_he]

One of the participants, however, pointed out the inverse phenomenon - a very wellknown popularizer of pseudo-scientific content in the Polish media.

How about this example? On YouTube, there is the channel of Mr Zięba. This is a person who propagates pseudo-scientific content. He sits down in front of the camera and does a story, often an hour and a half long, where he speaks calmly, convincingly. [PL_VAX_F_25-34_he]

There was barely any reference to public figures in relation to the topic of vaccines in the consultations in both countries.

\subsubsection{Practitioners}

Conversely, health practitioners are a source of scientific information only mentioned in relation to vaccines. The importance of health professionals-doctors and nurses, but more often the former - as a source of reliable information was frequently highlighted by the participants. Other professionals, like pharmacists, were mentioned a few times, but without assessing their reliability. Trust in doctors was justified by an interpersonal relationship that relies on empathy. Several participants in Portugal mentioned they did not question the doctors' recommendations since they already trusted prior information from that same doctor.

So, I think that I would only have doubts if I was actually recommended to take the vaccine or not. If it was recommended directly by the doctor, then, I would have the same opinion; I wouldn't question what the doctor said, I would believe him. [PT_VAX_F_25-34_he]

In Poland, participants underlined the fact that doctors studied for a long period and had to swear an oath. Also, they often have many years of experience in treating patients, so if they recommend a vaccination, it was because it was needed. Additionally, one participant 
emphasized the close relationship established with the family doctor or paediatrician as a driver for trust.

When it comes to my children, it's from the doctor. First of all, from the family doctor. And the paediatrician who took care of my children from the beginning... [PL_ VAX_M_45-54_he]

Though this is the general trend, in Portugal, a small number of participants stated they did not trust the doctor-especially in cases where different doctors make different recommendations. One participant suggested that trust could not be blind. In fact, a few participants noted a change in the approach as citizens increasingly question the information provided by doctors.

For a long time the idea that, if the doctor says, 'it's because it's like this, it's because it's good', that was enough. And now, with more access to information and misinformation, people are starting to question these things much more. So, this reliable information, easy to access, is missing. That is the way people can say, ok, I do this because of A, B and C. And not just because the doctor told me, and apparently it's very good. [PT_VAX_F_25-34_he]

In Poland, the participants also identified a generational shift. Widespread access to information, increasingly popular anti-vaccination debates, and media questioning the necessity of vaccines have had an impact on attitudes. The customary acceptance of doctors' recommendations, without discussion and without seeking additional information, is no longer the rule.

\section{Discussion}

Our analysis shows that motives used to justify reasons for trust and mistrust in different institutional and individual actors as conveyors of science information are manifold. Participants assessed the sources of scientific information using four different criteria: expertise, motivation, independence and commitment.

Expertise refers to having specialised knowledge on a specific subject or topic. It is associated with scientific evidence and methods, but also with experience. These issues are central to assessing science information, but they become particularly prominent when justifying trust in scientists, health practitioners or international political institutions that work in the field of climate change and vaccines. They are considered actors that produce, or rely on, a body of research that is based on scientific methods and are experts on the topic. On the other hand, the participants criticised actors that are not experts and that tend to make claims regarding the two topics discussed, disregarding scientific knowledge on the issue.

Independence refers to the ability to not be subject to external pressures, to be able to research, discuss and debate these issues without being restricted by external agendas or constraints. National institutions in Poland, for example, are considered more prone to external pressures than international ones, and as such, are more criticised by the participants. Public/private financing of civil society organisations or research centres is sometimes viewed as problematic because it can compromise the perceived independence of these organisations.

Motivation has to do with the reasons associated with the actors' intentions and work in this specific topic. Orientation to the common good, benevolence and social responsibility 
are seen as motives for trusting sources of scientific information. This is the case, for example, of the justifications used by some participants towards civil society organisations or public figures. On the other hand, economic interests, private agendas, extremism and instrumental polarisations are considered problematic and used as reasons to mistrust sources of scientific information.

Finally, commitment. In this case, the level of engagement to the cause, a consistent behaviour and a clear position throughout the years is considered a reason for trust. This justification is often given in relation to actors that are not necessarily experts in the field, like celebrities or public figures. So, their commitment to the cause is evaluated through the level of engagement, long-term involvement and behaviour consistency. On the other hand, inconsistencies are often seen as proof of hidden motives or personal agendas, thus used to criticise actors like politicians, private companies or some public figures.

Our data also show that perceptions of institutional and individual actors as sources of information about scientific issues are affected by the topic's visibility and presence in the public sphere. At the time of the consultations (September and November 2019), climate change was a "hot topic" in comparison to vaccines. This was the result of contextual dynamics at both the international and national levels. This difference in visibility helps to explain, for example, why the number of public figures mentioned on the topic of climate change was so high compared with vaccines. It also contributes to the fact that there were more mentions of polarisation and politicisation of climate change debates. In Portugal, this was discussed mostly at the international level—referencing politicians like Trump and Bolsonaro, but also activists like Greta Thunberg as examples. In Poland, politicisation was discussed within the national political context and the role of politicians, not least because the Polish consultation was only two weeks before the general election.

Vaccines, on the other hand, was a less political topic at the time. Nevertheless, in Poland, some participants mentioned the rise of the anti-vaccination movements-a threat that, as Kahan (2016) noted, creates difficulties in the science communication environment. This anti-vaccination movement found fertile ground in the current media environment, re-emerging from time to time, whereas climate change had a more continuous presence. There were also differences in how the participants perceived the level of governance of these two topics: vaccines were much more discussed at the national level and climate change at the international level.

Another topic specificity concerns the role of health practitioners-in particular doctors-as mediators for scientific information related to vaccines. The participants award trust to those professionals based on their expertise, knowledge and length of educational and professional training. Conversely, vaccines are a topic much less associated with scientists than climate change. High trust in health professionals was already expected, as the literature pointed in that direction (see Leask et al., 2006 or Weingart \& Gunther, 2016). In the case of climate change, the participants mostly mentioned scientists as trusted sources and discussed issues related to scientific research more in-depth.

Although the participants in both countries criticised the involvement of private companies because of their interests and motivations, some variation can be found between topics. In general, the participants associated companies with potential vested interests and being more committed to profit than the common good (a trend already identified by Hendriks et al., 2016). In the case of vaccines, the concrete actions of pharmaceutical companies were thoroughly discussed by the participants, almost unanimously assessing them as a driver of mistrust - although a few exceptions to this dominant representation were found in Poland. When these companies were linked to governments or scientists, these actors were also perceived more negatively. This is in line with Krause et al. (2019), 
who suggested that scientists employed by companies face lower levels of trust. In climate change, the involvement of private actors was perceived as slightly more nuanced, especially in Poland, as the participants in Portugal still believe that companies tend to favour their own private interests and see their intervention in this field as an opportunity to benefit from it.

One of the differences between countries we found concerns how the participants made sense of the relationship between the national and international contexts. In Portugal, the international context was discussed autonomously, while in Poland, it was often mentioned in relation to the national context, especially with regard to institutions. This seems to show a divergent perception of national institutions, particularly governmental ones. At a national level, in Poland, politicians were not only mentioned more, but they were also more distrusted in general. The participants in the Polish consultation perceived the topic of climate change as highly politicised, i.e. used by politicians as an element of party disputes or pre-election campaigns. Moreover, according to participants from both countries, politicians often ignored the knowledge provided by scientists and repeatedly denied that the climate is undergoing any change as a result of human activity. This stance on climate change may be attributed to the political ideology of the current government (i.e. conservative-see McCright \& Dunlap, 2011 and McCright et al., 2013) and to the economic and symbolic value that fossil fuels, in particular coal, still have in Poland (Kuchler \& Bridge, 2018).

Science and scientists seem to be better trusted in Portugal than in Poland, where some concerns about them were raised. During the discussions, in particular, about climate change, the independence of scientists in Poland was questioned a few times, since they depend on external funding, either public or private, which could curb their independence in developing their research. Therefore, the idea of freedom from external pressures, either political or economic, is fundamental to trust, which is consonant with the literature of this area (see, for instance, Borchelt, 2008). Interestingly, in Poland, some participants considered that the private funding of scientific research could be less problematic than links between research and politics, which must be seen in the light of the data about trust in national institutions, as previously mentioned, and the broader context of political trust in post-Soviet regimes (Latusek \& Cook, 2012). One explanation for this is the low culture of science communication in Poland (Warwas et al., 2021).

Another important insight from our analysis is that trust and mistrust in science information sources is not only affected by topic and national context, but also seems to be constructed differently. In alignment with the arguments of Van De Walle and Six (2014), we found differences in how participants expressed their motives for trust in the different actors.

In some cases, this trust seemed to be built in unquestioned confidence (participants that mostly justified their trust in international institutions, doctors or scientists in terms of them being more credible). For these participants, the trustworthiness of these actors is not questioned (because of their perceived status and reputation). There is a confident, positive expectation regarding their role, expertise and independence.

In other cases like public figures (celebrities, activists, etc.), we saw a justified trust that has to be explicitly supported in relation to the actors' motives, level of engagement and consistency. Again, there is a positive expectation regarding those actors that, in line with what Hendriks et al. (2016) found, is based on an active perception of the source's integrity and benevolence. However, in contrast with the first group, this trust is not associated with their role and expertise and must be earned through their behaviour and perceived commitment. 
Many of the criticisms made about sources of science information were mostly due more to reflexive vigilance (Hendriks et al., 2016; Van De Walle \& Six, 2014) than active distrust. In this case, the participants expressed concern about the actor's extremism, contradictions or inconsistencies (talk vs action). However, this criticism does not necessarily imply distrust, but rather an awareness of the factors that might affect the actors' objectivity. The participants do not necessarily distrust the actors they criticise, but they express a reflexive trust that translates into lower levels of trust in the information they convey. This is the case, for example, with some of the criticism regarding public figures or civil society organisations, but also research centres, or even scientists, when their independence or commitment is called into question.

In contrast, the criticism levelled at other actors, like some international politicians in Portugal, national politicians in Poland (on the topic of climate change) or private companies in both countries (on both topics), was of a different nature. In these cases, the actors are actively distrusted as conveyors of scientific information. The difference in relation to the reflexive vigilance we mentioned earlier is that this distrust is shaped by their perceived motives and negative intent due to the pursuit of self-interest (Weingart \& Guenther, 2016). In this case, it is evidenced by their active irresponsibility, inconsistency, the politicisation of scientific issues, and a focus on financial gains or opportunism. As we have seen, this perception is, in turn, mediated by national levels of institutional distrust and topic specificities.

\section{Conclusion}

This article aimed to explore citizens' perceptions about trust and distrust in different sources of scientific information. Based on a grounded qualitative analysis of group discussions conducted during public consultations in two countries—Poland and Portugal—and two topics, climate change and vaccines, we were able to identify four main criteria used by citizens to justify their trust/mistrust in both institutional and individual actors as conveyers of science information, namely, expertise, independence, motivation and commitment. These criteria were used differently depending on the source of scientific information but also varied in terms of the topic discussed and national context. Last, based on the different justifications for trust assessment mobilized by the participants, we also found different ways participants expressed their trust and mistrust towards individual and institutional sources of information: unquestioned confidence, justified trust, reflexive trust and active distrust. This typology differentiates trust from distrust and considers lower levels of trust the result of a reflexive vigilance, that is associated with an awareness of the factors that might affect the actors' objectivity. Active distrust, on the other hand, means that citizens actively disbelieve the actor's role as conveyors of scientific information.

As Van De Walle and Six (2014) explain, the importance of understanding how levels of trust and active distrust are constructed is related to the fact that these are not only related to attitudes, but also behaviours. The complexity of this relation has become even more evident recently, during the COVID-19 pandemic (Entradas, 2021; Petersen et al., 2021). As we have shown in our analysis, trust, lack of trust and distrust in relation to sources of information vary in terms of actors, topics and countries. These differences become more evident when we consider the arguments that support trust/mistrust in the sources of information. Studies that consider trust and distrust in science as a continuum that can be easily measured across topics, and without considering national specificities, might miss 
important insights into how people make sense of the information they receive, the criteria they use to evaluate the sources of this information, and what causes active distrust in scientific information sources and scientific knowledge.

The credibility of science depends on the process of disseminating scientific information and on the sources of science information (Weingart \& Guenther, 2016). Science-related topics such as climate change and vaccines are complex as they present an expanded ecosystem that goes beyond scientists, science institutions and science communicators to include many other actors. That means citizens find or connect with scientific information through multiple sources, going through a complex and multidimensional process in order to assess trust/mistrust of those sources. This will affect the degree of attention they pay to the actor, as well as whether they believe in the scientific information, and then take science-related decisions. By comparing public trust and distrust in relation to individual and institutional actors from two countries with different political landscapes on two controversial scientific topics, we were able to better clarify the multiple ways citizens assess the trustworthiness of scientific information. So, an implication of our study is the importance of comparative qualitative research to better understand the process of trust-building in science. This is a multi-layered process that could benefit from further qualitative analysis on how trust and distrust in sources of information are differently constructed and what their implications are for science communication.

Funding Data for this article is based on the project CONCISE Communication role on perception and beliefs of EU Citizens about Science. This project has received funding from the European Union's Horizon 2020 research and innovation programme under grant agreement No 824537.

Data Availability Data not available (qualitative).

Code Availability Not applicable.

\section{Declarations}

Ethics Approval As with all European Union funded projects, the project in which this article is based has been subjected to an ethics assessment. The project had an Ethics Advisor, a description of the technical and organizational measures that will be implemented to safeguard the rights and freedoms of the data subjects/ research and performed an analysis of the potential risk the proposed research raises in regard to the vulnerable populations, and the measures to protect them and minimize the risk of their stigmatization.

Consent to Participate All participants in the public consultations received information about the project and signed a consent form stating that they received sufficient information, that they agreed with participating in the project and they were aware that they could withdraw at any moment. They signed another consent form pertaining to sound and visual recordings of the consultation for scientific and educational purposes.

Conflict of Interest The authors declare that they have no conflict of interest.

\section{References}

Allum, N., Sturgis, P., Tabourazi, D., \& Brunton-Smith, I. (2008). Science knowledge and attitudes across cultures: A meta-analysis. Public Understanding of Science, 17(1), 35-54.

Azarian, R. (2011). Potentials and limitations of comparative method in social science. International Journal of Humanities and Social Science, 1(4), 113-125. 
Bauer, M. W. (2008). Survey research and the public understanding of science. In M. Bucchi \& B. Trench (Eds.), Handbook of public communication of science and technology (pp. 125-144). Routledge.

Borchelt, R. (2008). Public relations in science: Managing the trust portfolio. In M. Bucchi \& B. Trench (Eds.), Handbook of Public Communication of Science and Technology (pp. 147-157). Routledge.

Carvalho, A., Schmidt, L., Santos, F. D., \& Delicado, A. (2014). Climate change research and policy in Portugal. Wiley Interdisciplinary Reviews: Climate Change, 5(2), 199-217.

Charmaz, K. (2006). Constructing grounded theory: A practical guide through qualitative analysis. SAGE Publications.

Cologna, V., \& Siegrist, M. (2020). The role of trust for climate change mitigation and adaptation behaviour: A meta-analysis. Journal of Environmental Psychology, 69, 101428. https://doi.org/10.1016/j. jenvp.2020.101428

Dierkes, M., \& von Grote, C. (2005). Between understanding and trust: The public, science and technology. Routledge.

Entradas, M. (2021). In Science We Trust: The Effects of Information Sources on COVID-19 Risk Perceptions. Health Communication. https://doi.org/10.1080/10410236.2021.1914915

European Commission (2019). Standard EB 92: Public opinion in the European Union - Wave EB92.3. https://op.europa.eu/en/publication-detail/-/publication/5e407e8b-148d-11e9-81b4-01aa75ed71a1. Accessed 26 Nov 2021.

Gallup (2019) Wellcome Global Monitor - First Wave Findings. How does the world feel about science and health?, Apr-Dec 2018

Goldenberg, M. J. (2016). Public misunderstanding of science? Reframing the problem of vaccine hesitancy. Perspectives on Science, 24(5), 552-581.

Gonçalves, M. E., \& Castro, P. (2003). Science, culture and policy in Portugal: A triangle of changing relationships? Portuguese Journal of Social Science, 1(3), 157-173.

Gregory, J., \& Miller, S. (1998). Science in public: Communication, culture, and credibility. Plenum Press.

Hamilton, L. C., Hartter, J., \& Saito, K. (2015). Trust in scientists on climate change and vaccines. SAGE Open, 5(3), 2158244015602752.

Haywood, B. K., \& Besley, J. C. (2014). Education, outreach, and inclusive engagement: Towards integrated indicators of successful program outcomes in participatory science. Public Understanding of Science, 23(1), 92-106. https://doi.org/10.1177/0963662513494560

Hendriks, F., Kienhues, D., \& Bromme, R. (2016). Trust in science and the science of trust. In B. Blöbaum (Ed.), Trust and communication in a digitized world (pp. 143-159). Springer.

Larson, H., et al. (2018). State of vaccine confidence in the EU 2018. Luxembourg: Publications Office of the European Union 10 (2018): 241099

Kahan, D. M. (2016, August 23). Protecting the Science Communication Environment: The Case of Childhood Vaccines. The Cultural Cognition Project, Working Paper No. 244, Retrieved from https://ssrn.com/abstract=2828136 or https://doi.org/10.2139/ssrn.2828136. Accessed 26 Nov 2021.

Kozłowski, J. (2011). Monitoring Policy and Research Activities on Science in Society in Europe (MASIS) National Report. DG Research.

Krause, N. M., Brossard, D., Scheufele, D. A., Xenos, M. A., \& Franke, K. (2019). Trends-Americans' trust in science and scientists. Public Opinion Quarterly, 83(4), 817-836.

Krouwel, A., \& Abts, K. (2007). Varieties of Euroscepticism and populist mobilization: Transforming attitudes from mild Euroscepticism to Harsh Eurocynicism. Acta Politica, 42(2-3), 252-270.

Kuchler, M., \& Bridge, G. (2018). Down the black hole: Sustaining national socio-technical imaginaries of coal in Poland. Energy Research \& Social Science, 41, 136-147.

Latusek, D., \& Cook, K. S. (2012). Trust in transitions. Kyklos, 65(4), 512-525.

Laufer, W. S. (2003). Social accountability and corporate greenwashing. Journal of Business Ethics, 43(3), 253-261.

Leask, J., Chapman, S., Hawe, P., \& Burgess, M. (2006). What maintains parental support for vaccination when challenged by anti-vaccination messages? A qualitative study. Vaccine, 24, 7238-7245. https://doi.org/10.1016/j.vaccine.2006.05.010

Lewandowsky, S., Gignac, G. E., \& Oberauer, K. (2013). The role of conspiracist ideation and worldviews in predicting rejection of science. PloS one, 8(10), e75637.

Lewenstein, B. V. (1992). The meaning of public understanding of science in the United States after World War II. Public Understanding of Science, 1(1), 45-68.

Lewicki, R. J., McAllister, D. J., \& Bies, R. J. (1998). Trust and distrust: New relationships and realities. The Academy of Management Review, 23(3), 438-458. 
Matkowska-Kocjan, A. (2018). Najczęstsze problemy w realizacji szczepień ochronnych, [The most common problems in the implementation of preventive vaccinations]. Forum Zakazeń, 9(5), 299-302.

McCright, A. M., \& Dunlap, R. E. (2011). The politicization of climate change and polarization in the American public's views of global warming, 2001-2010. The Sociological Quarterly, 52(2), 155-194.

McCright, A. M., Dentzman, K., Charters, M., \& Dietz, T. (2013). The influence of political ideology on trust in science. Environmental Research Letters, 8(4), 044029.

Mejlgaard, N., Bloch, C., Degn, L., Nielsen, M. W., \& Ravn, T. (2012). Locating science in society across Europe: Clusters and consequences. Science and Public Policy, 39(6), 741-750. https://doi. org/10.1093/scipol/scs092

Miller, S., Caro, P., Koulaidis, V., De Semir, V., Staveloz, W., \& Vargas, R. (2002). Report from the expert group-benchmarking the promotion of RTD culture and public understanding of science. European Commission.

Pechar, E., Bernauer, T., \& Mayer, F. (2018). Beyond political ideology: The impact of attitudes towards government and corporations on trust in science. Science Communication, 40(3), 291-313.

Petersen, M. B., Bor, A., Jørgensen, F., \& Lindholt, M. F. (2021). Transparent communication about negative features of COVID-19 vaccines decreases acceptance but increases trust. Proceedings of the National Academy of Sciences of the United States of America, 118(29) e2024597118. https:// doi.org/10.1073/pnas.2024597118

Pieczka, M., \& Escobar, O. (2013). Dialogue and science: Innovation in policy-making and the discourse of public engagement in the UK. Science and Public Policy, 40(1), 113-126. https://doi.org/ 10.1093/scipol/scs073

Raithatha, N., Holland, R., Gerrard, S., \& Harvey, I. (2003). A qualitative investigation of vaccine risk perception amongst parents who immunize their children: A matter of public health concern. Journal of Public Health, 25(2), 161-164.

Sanz-Menéndez, L., \& Cruz-Castro, L. (2019). The credibility of scientific communication sources regarding climate change: A population-based survey experiment. Public Understanding of Science, 28(5), 534-553. https://doi.org/10.1177/0963662519840946

Sarathchandra, D., \& Haltinner, K. (2020). Trust/distrust judgments and perceptions of climate science: A research note on skeptics' rationalizations. Public Understanding of Science, 29(1), 53-60. https://doi. org/10.1177/0963662519886089

Stewart, D. W. \& P. N. Shamdasani. (1990). Focus Groups: Theory and Practice. Vol. 1. Applied Social Research Methods Series. Sage Publications, Inc.

Tlili, A., \& Dawson, E. (2010). Mediating Science and Society in the EU and UK: From InformationTransmission to Deliberative Democracy? Minerva, 48(4), 429-461. https://doi.org/10.1007/ s11024-010-9160-0

Warwas I., Dzimińska M., \& Krzewińska A. (eds.) (2021). Komunikacja naukowa w Polsce. Partycypacja. Dialog. Zaufanie [Science communication in Poland. Participation. Dialogue. Trust]. Wydawnictwo Uniwersytetu Łódzkiego

Weingart, P., \& Guenther, L. (2016). Science communication and the issue of trust. Journal of Science Communication, 15(5), C01. https://doi.org/10.22323/2.15050301

Wynne, B. (2006). Public engagement as a means of restoring public trust in science-hitting the notes, but missing the music? Public Health Genomics, 9(3), 211-220.

Van De Walle, S., \& Six, F. (2014). Trust and Distrust as Distinct Concepts: Why Studying Distrust in Institutions is Important. Journal of Comparative Policy Analysis: Research and Practice, 16(2), 158-174. https://doi.org/10.1080/13876988.2013.785146

Yearley, S. (2005). What Does Science Mean In The "Public Understanding Of Science"? In M. Dierkes \& C. von Grote (Eds.), Between understanding and trust: the public, science and technology. Routledge.

Publisher's Note Springer Nature remains neutral with regard to jurisdictional claims in published maps and institutional affiliations. 